\title{
Husbands' Knowledge of Breast Cancer and Their Wives' Attitudes and Practices Related to Breast Cancer Screening in Saudi Arabia: Cross-sectional Online Survey
}

Afnan Abdulnasir Sabgul ${ }^{1,2}$, MHA; Ameerah M N Qattan², PhD; Rubayyat Hashmi ${ }^{3,4}$, MSc; Mohammed Khaled Al-Hanawi², $\mathrm{PhD}$

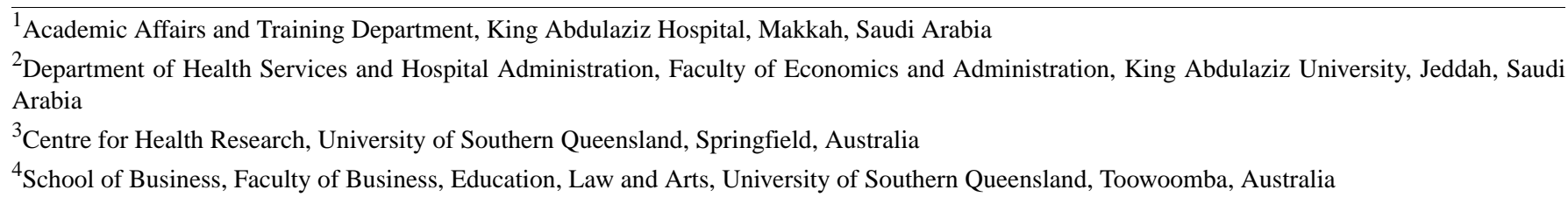

Corresponding Author:

Mohammed Khaled Al-Hanawi, PhD

Department of Health Services and Hospital Administration

Faculty of Economics and Administration

King Abdulaziz University

University Building 125

Faculties Street

Jeddah, 80200

Saudi Arabia

Phone: 966556522222

Email: mkalhanawi@kau.edu.sa

\section{Abstract}

Background: Despite Saudi Arabia's free and well-established cancer care program, breast cancer incidence and mortality are rising. Husbands' knowledge, and wives' attitudes and practices related to breast cancer screening are not well understood in Saudi Arabia.

Objective: The aim of this study was to investigate husbands' knowledge, and wives' attitudes and practices related to breast cancer screening in Saudi Arabia.

Methods: This cross-sectional study collected data from 403 husbands in the holy city of Makkah through an online self-reported questionnaire over a period of 2 months, from May 6 to July 7, 2020. Tabulation, bivariate, and multiple regression analyses were the major tools used for data analysis. Multivariate logistic regressions were used to examine the association between husbands' knowledge and wives' behavior regarding breast cancer screening methods.

Results: Husbands' knowledge score (a 1-point increase) was significantly associated with the wives' utilization of mammograms (adjusted odds ratio [AOR] 1.089, 95\% CI 1.024-1.159) and breast self-examination (AOR 1.177, 95\% CI 1.105-1.255). Husbands' knowledge also influenced the wives' attitudes toward learning about breast self-examination (AOR 1.138, 95\% CI 1.084-1.195). There was no significant association between husbands' knowledge and wives' utilization of clinical breast examination. However, richer husbands showed a socioeconomic gradient concerning their wives' utilization of clinical breast examinations (AOR 2.603, 95\% CI 1.269-5.341).

Conclusions: Overall, husbands' knowledge of breast cancer influences wives' attitudes and practices related to breast cancer screening methods in Saudi Arabia. Thus, interventions delivered to husbands might increase breast cancer awareness and survival.

(J Med Internet Res 2021;23(2):e25404) doi: 10.2196/25404

\section{KEYWORDS}

attitude; breast cancer; husbands; knowledge; Saudi Arabia; screening 


\section{Introduction}

Breast cancer is the leading cause of cancer-related deaths in women of over 100 countries, and is responsible for approximately $15 \%$ of all cancer deaths in women worldwide [1]. In the Kingdom of Saudi Arabia (KSA), breast cancer incidence increased by approximately 10 -fold during the period of 1990-2016 [2]. Moreover, breast cancer at an advanced stage is more common in Saudi women compared to women from Western countries [3]. The incidence of breast cancer is also expected to show a rising trend in the next decade in the KSA due to the elderly age structure of the Saudi community $[4,5]$. If the current growth rate of breast cancer incidence in the KSA continues, it is expected to become the driving force in the projected 2015-2030 economic burden of US \$159.44 billion for all cancers [6].

Breast cancer awareness contributes to the early detection of cancer presentation, and is thus necessary to reduce breast cancer incidence and mortality [7]. Evidence also suggests that a substantial proportion of breast cancer cases are self-detected [8]. Thus, high-risk groups need to be aware of breast cancer risk factors and risk reduction strategies to avoid being diagnosed in the late stages of cancer [9]. Knowledge about breast cancer can also promote utilization of the recommended screening methods for the timely detection of breast cancer $[10,11]$. However, women tend to have a limited level of knowledge about breast cancer in the KSA [12-14]. In addition, despite free access to health care services in the KSA [15], the level of breast cancer screening practices remains low [16]. Recent studies have also found marked socioeconomic gradients in breast cancer screening uptake among Saudi women [17].

Similar to several countries in the Middle East and the Arab world, the KSA has a conservative culture, and men usually manage many of the decisions, choices, and actions of women $[18,19]$. A sociocultural barrier exists for breast cancer screening practices, and failure to account for such barriers can undermine the success of well-established cancer care programs [20]. Although some studies have explored men's knowledge in relation to women's attitudes and practices related to breast cancer screening methods $[18,19,21,22]$, these studies either did not explore the association between men's knowledge and their wives' practices regarding breast cancer screening or did not control for socioeconomic gradients. Thus, the degree to which men's knowledge can support women to take actions for better protection from breast cancer in a country such as the KSA is not fully understood. Understanding such a mechanism might help in developing breast cancer awareness interventions and reduce breast cancer mortality through early detection.

The aim of this study was to investigate the potential effect of husbands' knowledge on their wives' attitudes and practices related to breast cancer screening in the holy city of Makkah in the Makkah region of western Saudi Arabia, located 70 kilometers inland from Jeddah. Approximately $26 \%$ of the KSA population live in the Makkah region [23]. Makkah also hosts the largest annual Muslim pilgrimage, the Hajj, and is thus regarded as a holy city among Muslims. Moreover, the city has a diverse population, with different lifestyle patterns and

economic statuses. To understand the impact of husbands' knowledge in Makkah city, we controlled for the possible effects of socioeconomic characteristics on wives' attitudes and practices related to breast cancer screening in this study.

\section{Methods}

\section{Study Setting and Sample}

This cross-sectional study was carried out in Makkah city of the Makkah region in the KSA from May 6 to July 7, 2020. Given the social/physical distancing measures implemented in the country because of the COVID-19 pandemic, data were collected via an online self-reported questionnaire using a Google Drive website. The link was distributed to potential participants via social media, including Twitter and WhatsApp groups.

This study included participants who were residents of Makkah city and were male partners (ie, husbands) aged between 20 and 80 years. According to the latest KSA census, Makkah has a total of 434,248 married men (ie, husbands) [23]. The minimum sample size necessary for the study was calculated to be 384 husbands (margin of error of 5\%, confidence level of $95 \%, 50 \%$ response distribution, based on the total 434,248 husbands in the region).

The questionnaire was developed by the authors based on several previous studies $[3,12,14,19,20]$. The questionnaire consisted of three main parts: sociodemographic characteristics of the participants, knowledge about breast cancer and screening methods, and knowledge of wives' practices and attitudes related to breast cancer screening. The questionnaire was written in Arabic. It was initially drafted by two authors (AS and MA) in English and then translated to Arabic by AQ. The questionnaire was also back-translated to English by two bilingual speakers, and reviewed by academic researchers from the Department of Health Services and Hospital Administration at King Abdulaziz University to maintain the original construct and to ensure the meaning of the content.

On the first page of the online questionnaire, participants were provided with the study background, aim, and objectives. They were informed that they did not have to complete the questionnaire and were free to withdraw at any point without providing a reason. They were also informed that there would be no sensitive personal questions, and all information provided would be anonymous, confidential, and used for research purposes only. Participants aged 20 years or over living in Makkah city, who understood the content of the questionnaire, and agreed to participate in the study were instructed to start the questionnaire. Online informed consent was obtained from all participants before proceeding with the questionnaire.

\section{Variables}

In this study, we defined four outcome variables: variables related to wives' practices of breast self-examination (BSE) (yes, no, and unsure), clinical breast examination (CBE) (yes, no, and unsure), and mammograms (yes, no, and unsure), and a variable related to wives' attitudes toward learning about BSE (yes, no, and unsure). The main exposure variable of this study was the husbands' knowledge scores. Using predetermined 
answer keys based on medical evidence, each correctly answered knowledge question was awarded one knowledge point. Incorrectly answered questions or "I don't know" responses were awarded zero knowledge points.

There were 20 knowledge questions in the questionnaire, including two questions on BSE (age of commencement and frequency), one question on CBE (age of commencement), two questions on mammograms (age of commencement and frequency), five questions on symptoms (changes in breast size, nipple morphology, nipple dryness, nipple discharge, and lymphadenopathy), six questions on risk factors (use of contraceptives, hormone replacement therapy, overexposure to radiation, smoking, hereditary, and old age), and four questions on protective factors (natural breastfeeding, sports/exercise practices, early conception, and balanced and healthy diet). The total knowledge score was computed by adding up the points for each of the 20 breast cancer knowledge questions, yielding a total breast cancer knowledge score between 0 and 20 .

Multivariate logistic regression analyses were performed controlling for the husbands' sociodemographic covariates. We used age, nationality, education, occupation, and household monthly income level as the sociodemographic control variables. Age was categorized as 20-29 (reference category), 30-39, $40-49,50-59$, and $\geq 60$ years. Nationality was categorized as non-Saudi (reference category) and Saudi. Education was categorized as high school education level or less (reference category) and college/university degree or higher. Occupation was split into the categories of unemployed or retired (reference category), self-employed, government employee, and private sector employee. Household monthly income was grouped into two categories: less than 10,000 Saudi Riyal (SR) (reference category) and $\geq 10,000 \mathrm{SR}$ ( $1 \mathrm{SR}=\mathrm{US} \$ 0.27$ ).

\section{Statistical Analyses}

Tabulation, bivariate, and multiple regression analyses were the major data analytic tools used in this study. Means (SD) are used to describe the continuous variables, whereas frequency and percentages are used to describe the categorical variables. The nonparametric univariate $\chi^{2}$ goodness-of-fit test was used to assess the statistical significance of the husbands' indicators of knowledge on breast cancer signs and preventive measures. Multivariate logistic binary regression analysis was used to assess the correlations between the husbands' knowledge about breast cancer and their sociodemographic, educational, and economic factors with their wives' various types of breast screening behaviors. The associations are expressed as adjusted odds ratios with 95\% CIs. The SPSS version 20 software package was used to perform all statistical analyses.

\section{Ethical Clearance}

All procedures performed in this study involving human participants were performed in accordance with the ethical standards of the institutional or national research committee and with the 1964 Helsinki Declaration and its later amendments or comparable ethical standards. This study was reviewed and approved by the King Abdulaziz University Research Ethics Committee, and was designed and performed in accordance with the ethical principles established by the university. This study also received ethical approval from the Ministry of Health of the KSA (IRB no: H-02-K-076-0320-275). Online informed consent to participate was secured from all respondents who participated in this study. The data collection procedure was anonymous and as such no personal identifying information was collected. The data were stored on the first author's password-protected personal computer. An additional copy of the data was stored on a password-protected external drive kept by the first author to serve as a backup.

\section{Results}

\section{Demographic and Socioeconomic Characteristics of the Respondents}

A total of 445 participants completed the questionnaire. After excluding 42 respondents who reported living outside of Makkah city, the final sample consisted of 403 participants. Table 1 shows the diverse demographic and socioeconomic characteristics of the study participants.

The majority of participants were Saudi citizens, and the others comprised expatriate men residing in Makkah city. Of the 403 participants, over half were aged 40 or older, over three-quarters had a college/university or a postgraduate degree, and just over half worked in various governmental jobs. Over one-third of participants had a household monthly income of less than 10,000 SR. 
Table 1. Demographic and socioeconomic characteristics ( $\mathrm{N}=403)$.

\begin{tabular}{|c|c|c|}
\hline Characteristic & Frequency, n (\%) & $95 \% \mathrm{CI}$ \\
\hline \multicolumn{3}{|l|}{ Age (years) } \\
\hline $20-29$ & $64(15.9)$ & $12.7-19.1$ \\
\hline $30-39$ & $120(29.8)$ & $25.3-34.2$ \\
\hline $40-49$ & $106(26.3)$ & $22.1-30.3$ \\
\hline $50-59$ & $62(15.4)$ & 12.4-18.6 \\
\hline$\geq 60$ & $51(12.7)$ & $10.2-14.7$ \\
\hline \multicolumn{3}{|l|}{ Nationality } \\
\hline Non-Saudi & $56(13.9)$ & $10.7-17.1$ \\
\hline Saudi & $347(86.1)$ & $82.9-89.3$ \\
\hline \multicolumn{3}{|l|}{ Educational level } \\
\hline High school level or below & $85(21.1)$ & $17.4-24.6$ \\
\hline College/university degree & $248(61.5)$ & $57.3-66.2$ \\
\hline Postgraduate degree & $70(17.4)$ & $14.1-20.6$ \\
\hline \multicolumn{3}{|l|}{ Occupation } \\
\hline Retired/unemployed & $79(19.6)$ & $16.4-22.6$ \\
\hline Self-employed & $19(4.7)$ & $3.0-6.7$ \\
\hline Governmental employee & $214(53.1)$ & $48.6-57.8$ \\
\hline Private sector employee & $91(22.6)$ & $19.1-26.8$ \\
\hline \multicolumn{3}{|c|}{ Household monthly income (Saudi Riyal) $^{\mathrm{a}}$} \\
\hline 5000 & $39(9.7)$ & $7.2-12.4$ \\
\hline 5000 to $<7000$ & $37(9.2)$ & $6.7-11.9$ \\
\hline 7000 to $<10,000$ & $72(17.9)$ & $14.6-21.1$ \\
\hline 10,000 to $<15,000$ & $142(35.2)$ & $31.3-39.5$ \\
\hline 15,000 to $<20,000$ & $57(14.1)$ & $11.2-17.4$ \\
\hline 20,000 to $<30,000$ & $42(10.4)$ & 7.9-13.4 \\
\hline$\geq 30,000$ & $14(3.5)$ & $2.2-5.2$ \\
\hline
\end{tabular}

${ }^{\mathrm{a}} 1$ Saudi Riyal=US $\$ 0.27$.

\section{Husbands' Knowledge and Awareness of Female Breast Cancer}

Table 2 shows the husbands' knowledge and awareness of breast cancer screening methods, including BSE, CBE, and mammograms.

In general, the basic knowledge and awareness of female BSE, CBE, and mammograms was low among the husbands in Makkah city. The majority of the husbands had heard about female BSE; however, when asked about the stage at which women should start BSE, just over a quarter of the respondents correctly inferred that they should start from the age of 20 . The same proportion also correctly suggested that monthly BSE is recommended for women. In contrast, over half of the respondents had not heard about CBE, and only about $35 \%$ of the husbands correctly answered that the recommended time of $\mathrm{CBE}$ is from the age of 40 or when women have symptoms. Furthermore, approximately $60 \%$ of the husbands had heard about mammograms. However, less than half of the respondents correctly inferred that the recommended starting age of mammograms is from the age of 40 or higher. Similarly, only about a third of the husbands correctly suggested that the recommended frequency of mammograms for women is every 1-2 years.

The husbands' poor knowledge of breast cancer screening was also reflected in their wives' attitudes and practices related to these behaviors. As shown in Table 3, according to the husbands, only approximately $20 \%$ of the wives regularly self-examined their breasts or had ever had a CBE. Similarly, less than $20 \%$ of the wives had ever had a mammogram. However, over half of the husbands stated that their wives were willing to learn more about BSE.

The results related to the husbands' knowledge of female breast cancer symptoms, risk factors, and preventive measures are shown in Table 4. 
Table 2. Husbands' knowledge and awareness of breast self-exams (BSE), clinical breast exams (CBE), and mammograms (N=403).

\begin{tabular}{lll}
\hline Question & Frequency, $\mathrm{n}(\%)$ & \\
\hline BSE & & $95 \%$ CI \\
Have you ever heard of female BSE? & $107(26.6)$ & $22.8-31.0$ \\
$\quad$ No & $296(73.4)$ & $69.0-77.4$ \\
$\quad$ Yes & & $31.5-40.4$ \\
At what stage do you think women should start BSE? & $145(36.0)$ & $9.4-15.5$ \\
$\quad$ Do not know & $50(12.4)$ & $22.6-31.0$ \\
$\quad$ At puberty & $108(26.8)$ & $19.1-26.8$ \\
$\quad$ From the age of 20 & $92(22.8)$ & $1.0-3.0$ \\
$\quad$ From the age of 40 & $8(2.0)$ & $37.7-46.7$ \\
$\quad$ After menopause & & $4.5-8.4$ \\
How often should women undergo BSE? & $170(42.2)$ & $22.3-30.2$ \\
$\quad$ Do not know & $26(6.5)$ & $21.1-29.3$ \\
$\quad$ Weekly & $106(26.3)$ & \\
Monthly & $101(25.1)$ & \\
Annually & &
\end{tabular}

CBE

Have you ever heard of female CBE?

$\begin{array}{lll}\text { No } & 229(56.8) & 52.1-61.8 \\ \text { Yes } & 174(43.2) & 38.7-47.6 \\ \text { what age do you think women should start CBE? } & & 49.6-59.3 \\ \text { Do not know } & 220(54.6) & 1.5-4.6 \\ \text { At puberty } & 12(3.0) & 5.2-9.2 \\ \text { From the age of } 20 \text { or higher } & 29(7.2) & 30.0-39.0 \\ \text { From the age of } 40 \text { or when there are symptoms } & 139(34.5) & 0.0-1.7 \\ \text { After menopause } & 3(0.7) & \end{array}$

Mammogram

Have you ever heard of a mammogram?

$\begin{array}{llr}\text { No } & 161(40.0) & 35.2-44.4 \\ \text { Yes } & 242(60.0) & 55.6-64.5\end{array}$

At what age do you think women should start having mammograms?

$\begin{array}{lll}\text { Do not know } & 199(49.4) & 44.9-54.1 \\ \text { At puberty } & 3(0.4) & 0.0-1.7 \\ \text { From the age of } 20 \text { or higher } & 20(5.0) & 3.2-6.9 \\ \text { From the age of } 40 \text { or higher } & 169(41.9) & 37.5-46.2 \\ \text { After menopause } & 12(3.0) & 1.7-4.2\end{array}$

How often should women undergo a mammogram?

$\begin{array}{lll}\text { Do not know } & 210(52.1) & 47.4-56.5 \\ \text { Monthly } & 12(3.0) & 1.7-4.5 \\ \text { Every 1-2 years } & 145(36.0) & 31.5-40.7 \\ \text { Every 4 years } & 36(8.9) & 6.5-11.7\end{array}$


Table 3. Husbands' knowledge of their wives' practices and attitudes related to breast cancer screening ( $\mathrm{N}=403)$.

\begin{tabular}{|c|c|c|}
\hline Outcome variables & Frequency, $\mathrm{n}(\%)$ & $95 \% \mathrm{CI}$ \\
\hline \multicolumn{3}{|c|}{ Has your wife ever had a mammogram? } \\
\hline No & $334(82.9)$ & 79.4-86.4 \\
\hline Yes & $69(17.1)$ & $14.1-20.6$ \\
\hline \multicolumn{3}{|c|}{ Has your wife ever had a clinical breast exam? } \\
\hline No & $322(79.9)$ & 75.9-83.4 \\
\hline Yes & $81(20.1)$ & $16.6-23.6$ \\
\hline \multicolumn{3}{|c|}{ Does your wife self-examine her own breasts regularly? } \\
\hline No & $328(81.4)$ & 77.9-84.9 \\
\hline Yes & $75(18.6)$ & $15.1-22.1$ \\
\hline \multicolumn{3}{|c|}{ Do you think your wife is willing to learn more about breast self-examination? } \\
\hline No & $180(44.7)$ & $40-49.6$ \\
\hline Yes & $223(55.3)$ & $51.1-59.8$ \\
\hline
\end{tabular}

Table 4. Husbands' knowledge about female breast cancer symptoms, risk factors, and preventive measures (N=403).

\begin{tabular}{|c|c|c|c|c|c|c|}
\hline \multirow[t]{2}{*}{ Question } & \multicolumn{2}{|c|}{ Incorrect answer } & \multicolumn{2}{|c|}{ Correct answer } & \multirow[t]{2}{*}{$\operatorname{GOF}^{\mathrm{a}} \chi^{2}(d f=2)$} & \multirow[t]{2}{*}{$P$ value } \\
\hline & $\mathrm{n}(\%)$ & $95 \% \mathrm{CI}$ & $\mathrm{n}(\%)$ & $95 \% \mathrm{CI}$ & & \\
\hline \multicolumn{7}{|l|}{ Symptoms } \\
\hline The change in women's breast size is a sign of breast cancer & 285 (70.7) & $66.7-75.2$ & $118(29.3)$ & $25.1-33.0$ & 106.784 & $<.001$ \\
\hline Lymphadenopathy is a sign/symptom of breast cancer & $162(40.4)$ & $35.7-44.7$ & $241(59.6)$ & $55.3-64.3$ & 170.462 & $<.001$ \\
\hline Nipple skin dryness and peeling is a sign of breast cancer & $299(74.2)$ & $70.2-78.2$ & $104(25.8)$ & $22.0-29.8$ & 175.985 & $<.001$ \\
\hline Nipple discharge is a sign of breast cancer & $273(67.7)$ & $63.5-72.0$ & $130(32.3)$ & $27.8-36.7$ & 172.263 & $<.001$ \\
\hline Changes in nipple morphology is a sign of breast cancer & $268(66.5)$ & $61.8-71.1$ & $135(33.5)$ & $29.0-38.0$ & 167.29 & $<.001$ \\
\hline \multicolumn{7}{|l|}{ Risk factors } \\
\hline $\begin{array}{l}\text { Use of contraceptives is a possible risk factor for breast } \\
\text { cancer }\end{array}$ & $333(82.6)$ & 78.9-85.9 & $70(17.4)$ & $14.4-20.8$ & 150.02 & $<.001$ \\
\hline $\begin{array}{l}\text { Hormonal replacement therapy may predispose women to } \\
\text { breast cancer }\end{array}$ & $338(83.9)$ & $80.1-87.1$ & $65(16.1)$ & $13.2-19.6$ & 275.275 & $<.001$ \\
\hline $\begin{array}{l}\text { Overexposure to radiation may predispose women to breast } \\
\text { cancer }\end{array}$ & $160(39.7)$ & $35.2-44.7$ & $243(60.3)$ & $55.6-64.5$ & 209.037 & $<.001$ \\
\hline $\begin{array}{l}\text { Cigarette smoking is a risk factor for breast cancer among } \\
\text { women }\end{array}$ & $144(35.7)$ & $31.0-40.2$ & $259(64.3)$ & $60.3-68.7$ & 195.042 & $<.001$ \\
\hline Women may develop breast cancer due to hereditary factors & $123(30.5)$ & $26.1-35.0$ & $280(69.5)$ & $65.3-73.9$ & 260.164 & $<.001$ \\
\hline $\begin{array}{l}\text { Older age is a factor that enhances the chance of developing } \\
\text { breast cancer among women }\end{array}$ & $259(64.3)$ & $59.6-68.7$ & $144(35.7)$ & $31.5-40.0$ & 59.201 & $<.001$ \\
\hline \multicolumn{7}{|l|}{ Protective factors } \\
\hline $\begin{array}{l}\text { Natural breastfeeding may prevent against developing } \\
\text { breast cancer among women }\end{array}$ & $103(25.6)$ & $21.8-29.8$ & $300(74.4)$ & $70.5-78.2$ & 326.298 & $<.001$ \\
\hline Regular sports/exercise may protect against breast cancer & $128(31.8)$ & $27.4-36.3$ & $275(68.2)$ & $63.8-72.2$ & 258.169 & $<.001$ \\
\hline $\begin{array}{l}\text { Early conception before the age of } 30 \text { years may reduce } \\
\text { the chance of getting cancer among women }\end{array}$ & $325(80.6)$ & $77.2-84.6$ & $78(19.4)$ & $15.4-22.8$ & 258.854 & $<.001$ \\
\hline $\begin{array}{l}\text { A balanced and healthy diet may reduce the chance of de- } \\
\text { veloping breast cancer among women }\end{array}$ & $123(30.5)$ & $26.3-35.7$ & $280(69.5)$ & $65.3-73.7$ & 277.97 & $<.001$ \\
\hline
\end{tabular}

${ }^{\mathrm{a}} \mathrm{GOF}$ : goodness of fit. 
The most frequent symptom of breast cancer that had been correctly identified was the sign of lymphadenopathy, followed by changes in nipple morphology, nipple discharge, changes in breast size, and nipple skin dryness. Similarly, the most frequent risk factor of breast cancer mentioned by husbands was hereditary factors, followed by cigarette smoking, overexposure to radiation, older age, use of contraceptives, and hormonal replacement therapy. In addition, the most frequent protective factor of breast cancer known to husbands was natural breastfeeding, followed by a balanced and healthy diet, regular exercise, and early conception before the age of 30 .

The knowledge score of the husbands was calculated from the scores of the 20 knowledge questions shown in Tables 2 and 4. The score ranged from 0 to 20 , with a mean knowledge score of 8.31 points (SD 4.91). Those with a lower knowledge score were regarded as having poorer knowledge of breast cancer compared to those with a higher knowledge score. The knowledge score was then used to investigate any effects of the husbands' knowledge on their wives' attitudes and practices related to breast cancer screening. The details of the regression analyses are discussed in the following section.

\section{Regression Analyses}

Table 5 shows the results of the multivariate logistics regression analyses used to assess the adjusted association of husbands' sociodemographic characteristics and knowledge about breast cancer with their wives' attitudes and practices related to breast cancer screening. Husband age of 40-49, 50-59, and $\geq 60$ years was significantly associated with their wives' practices of mammogram screening. However, only age of 40-49 years was significantly associated with their wives' practices of CBE. Similarly, a husband age of 30-39 and 40-49 years was associated with their wives' practices of BSE. Only older husbands aged 60 years or more had significantly lower odds in terms of their wives' willingness to learn more about BSE.

The results also revealed that husbands who were employed in the private sector had more than a 4-times higher odds that their wives had performed mammography screening than those who were retired or unemployed. Similarly, the husbands with higher household monthly income levels $(\geq 10,000$ SR $)$ had approximately 2-times higher odds that their wife had undergone a mammogram and had more than 2-times higher odds that their wives had undergone a CBE. Additionally, the husbands' high knowledge score was significantly associated with their wives' utilization of mammograms and BSE, as well as their wives' willingness to learn more about BSE. However, no association between husbands' knowledge scores and wives' utilization of CBE screening was found (Table 5).

Table 5. Multivariate logistic regression analyses of the effects of husbands' knowledge on their wives' attitudes and practices related to breast cancer screening.

\begin{tabular}{|c|c|c|c|c|}
\hline Variables & $\begin{array}{l}\text { Wife underwent a mammo- } \\
\text { gram, } \text { AOR }^{\text {a }}(95 \% \mathrm{CI})\end{array}$ & $\begin{array}{l}\text { Wife underwent a CBE } \\
\text { AOR }(95 \% \mathrm{CI})\end{array}$ & $\begin{array}{l}\text { Wife underwent a } \mathrm{BSE}^{\mathrm{c}} \text {, } \\
\text { AOR }(95 \% \mathrm{CI})\end{array}$ & $\begin{array}{l}\text { Wife willing to learn more } \\
\text { about BSE, AOR (95\% CI) }\end{array}$ \\
\hline \multicolumn{5}{|l|}{ Age (years) } \\
\hline $30-39$ & $2.084(0.638-6.812)$ & $2.080(0.781-5.54)$ & $4.595(1.482-14.246)^{* * *}$ & $1.457(0.761-2.788)$ \\
\hline $40-49$ & $4.332(1.372-13.675)^{* *}$ & $3.207(1.22-8.425)^{* * *}$ & $4.363(1.352-14.079)^{* *}$ & $1.691(0.862-3.318)$ \\
\hline $50-59$ & $5.34(1.423-20.10)^{* *}$ & $2.764(0.897-8.515)$ & $2.852(0.722-11.263)$ & $1.188(0.522-2.705)$ \\
\hline$\geq 60$ & $6.54(1.325-32.56)^{* *}$ & $1.880(0.419-8.432)$ & $2.414(0.473-12.329)$ & $0.220(0.069-0.698)^{* *}$ \\
\hline Saudi nationality & $1.698(0.639-4.513)$ & $1.305(0.495-3.437)$ & $2.030(0.726-5.677)$ & $2.091(0.954-4.584)$ \\
\hline $\begin{array}{l}\text { College/university degree or } \\
\text { higher }\end{array}$ & $0.772(0.355-1.67)$ & $0.665(0.323-1.381)$ & $1.557(0.641-3.780)$ & $0.549(0.296-1.018)$ \\
\hline \multicolumn{5}{|l|}{ Occupation } \\
\hline Self-employed & $2.109(0.398-11.183)$ & $0.327(0.039-3.588)$ & $1.101(0.177-5.639)$ & $0.599(0.167-2.15)$ \\
\hline Government employee & $0.646(0.211-1.980)$ & $0.997(0.344-3.588)$ & $0.387(0.122-1.231)$ & $0.644(0.271-1.527)$ \\
\hline Private sector employee & $4.735(1.319-16.990)^{* *}$ & $2.677(0.789-9.084)$ & $1.394(0.401-4.844)$ & $1.097(0.409-2.939)$ \\
\hline $\begin{array}{l}\text { Household monthly income } \\
\geq 10,000 \mathrm{SR}^{\mathrm{d}}\end{array}$ & $1.965(0.925-4.174)$ & $2.603(1.269-5.341)^{* * *}$ & $1.222(0.602-2.479)$ & $0.710(0.411-1.228)$ \\
\hline Knowledge score & $1.089(1.024-1.159)^{* * *}$ & $1.045(0.989-1.108)$ & $1.177(1.105-1.255)^{* * *}$ & $1.138(1.084-1.195)^{* * *}$ \\
\hline
\end{tabular}

${ }^{\mathrm{a}} \mathrm{AOR}$ : adjusted odds ratio.

${ }^{\mathrm{b}} \mathrm{CBE}$ : clinical breast examination.

${ }^{\mathrm{c}} \mathrm{BSE}$ : breast self- examination.

${ }^{\mathrm{d}} \mathrm{SR}$ : Saudi Riyal (1 SR=US \$0.27).

$* P<.10, * * P<.05$, and $* * * P<.01$. 


\section{Discussion}

\section{Principal Findings}

Although previous studies have addressed the knowledge and attitude of breast cancer screening among Saudi women, this study illustrates the impact of husbands' knowledge on their wives' breast cancer screening behavior in Makkah city of the KSA using an online cross-sectional survey. The findings revealed that husbands' knowledge has an important impact on their wives' attitudes and practices related to the utilization of breast cancer screening methods. This study also showed socioeconomic gradients concerning wives' utilization of mammogram and $\mathrm{CBE}$.

Breast cancer survival is closely associated with cancer awareness [7,24]. Because of the conservative culture in the KSA, many women refrain from seeking medical advice until breast cancer presents at an advanced stage [25]. Moreover, some women cannot have any screening of their breasts without first obtaining approval from their male guardians [20]. Thus, men have an important role in supporting and encouraging women to obtain early diagnosis and treatment. However, the magnitude of the influence that husbands' knowledge of breast cancer has on their wives' screening behavior was unclear in earlier studies. Our findings have strengths that might be relevant in addressing the information needs of breast cancer patients [26] or implementing risk-stratified breast cancer prevention strategies [27].

One of the major findings of this study was that the husbands' knowledge was significantly associated with their wives' utilization of mammograms and BSE. This study also found that a 1-point increase in the husbands' knowledge scores on breast cancer increased the odds of mammogram utilization by approximately 1.1 times and increased the odds of BSE utilization by approximately 1.2 times. In addition, a 1-point increase in the husbands' knowledge scores on breast cancer increased the odds of their wives' being willing to learn about BSE by approximately 1.1 times. If considered cumulatively, our findings suggest that the husbands' knowledge substantially increased the probability of their wives' participation in mammogram and BSE screening methods. Similar findings were also reported in another study [19].

Most previous studies have not controlled for all socioeconomic factors when investigating husbands' knowledge about breast cancer [18-22]. However, several other studies found socioeconomic gradients in breast cancer incidence, mortality, and screening uptake behavior $[17,28,29]$. In our study, the findings of socioeconomic gradients were mixed, showing limited socioeconomic gradients in terms of mammogram (private sector employee) and CBE (income level) uptake. However, this study also found no association between education, nationality, and screening practices. This could be due to our small sample size. Despite the majority of our sample participants being highly educated, the level of breast cancer knowledge among the husbands in Makkah city was not satisfactory. Similar findings of men's poor knowledge about breast cancer were also reported in the Jeddah [21,22], Hail [3], and Asir [14,19] regions of Saudi Arabia, as well as in other countries such as Jordan [18] and Ghana [30].

In line with existing evidence [19], our study also found a significant association between the age of the husbands and their wives' utilization of mammograms, CBEs, and BSE, as well as their wives' attitudes toward learning about BSE. We found that only a husband age of 40-49 years had a significant relationship with CBE uptake, whereas almost all ages (40-49, 50-59, and 60 years or older) showed a significant association with mammogram uptake. BSE was usually performed by the wives of younger husbands (30-39 and 40-49 years), whereas the wives of elderly husbands (60 years or older) were less willing to learn about BSE. Our findings suggest that the age distribution of the husbands had a significant impact on their wives' utilization of screening methods and attitudes toward breast cancer.

In the KSA, a large number of breast cancer cases are discovered at late stages, which leads to a lower rate of recovery [31]. Despite free health services and free screening facilities, there is almost no use of mammograms in the KSA $[15,16]$. Thus, increasing the awareness about early detection tools for breast cancer is vitally important. Recent studies have found that breast cancer awareness interventions (eg, public health campaigns and educational programs) are effective to increase the uptake of BSE and mammogram behaviors, and to increase the probability of breast cancer screening attendance [32]. Studies have also found that target-based interventions can increase breast cancer awareness [9]. Our study findings indicate that there is a lot of work that needs to be done to improve cancer survival rates and to lower incidence rates. It is strongly recommended to empower women, raise cancer awareness, and remove barriers to fight breast cancer.

\section{Limitations}

The findings of this study should be interpreted in light of some limitations. This research concerned the Makkah region and urban settings only, where the majority of the men were well educated. In addition, the study design was cross-sectional in nature with the possibility of recall and self-reporting biases. Finally, the descriptive analysis cannot be generalized to all husbands in the KSA, as study participants were recruited through a convenience sampling method. However, care was taken to recruit participants that preserve the sociodemographic distribution of the KSA and, as already discussed, our descriptive analysis did not contradict the findings of past studies.

\section{Conclusions}

This study found evidence that husbands' knowledge about breast cancer has an important role in encouraging the breast cancer screening behaviors of their wives. Furthermore, the study findings documented limited knowledge about breast cancer among Makkah residents. Moreover, the wives of elderly husbands, according to their husbands' beliefs, are less willing to learn about BSE, whereas younger husbands' wives had higher odds of performing BSE. We also found some limited socioeconomic gradients regarding the utilization of mammograms and CBEs. These findings have important 
implications for conservative cultures where men play a crucial role in women's decisions and actions. Policies could be directed to raise breast cancer awareness, and interventions could be devised such that high-risk groups (eg, elderly or low socioeconomic status background) adhere to the recommended cancer screening protocol. Efforts should be made to empower women so that barriers to seeking medical help are alleviated. Future research is needed to evaluate whether implementing breast cancer awareness interventions increases cancer survival.

\section{Authors' Contributions}

Conceptualization: AS and MA; methodology: AS and MA; software: AS; validation: AS, MA, and AQ; formal analysis: AS; investigation: AS; data curation: AS and MA; writing —original draft preparation: AS, AQ, RH, and MA; writing-review and editing: AS, AQ, RH, and MA; supervision: MA and AQ; project administration: AS, MA, and AQ. All authors read and agreed to the published version of the manuscript.

\section{Conflicts of Interest}

None declared.

\section{References}

1. Bray F, Ferlay J, Soerjomataram I, Siegel RL, Torre LA, Jemal A. Global cancer statistics 2018: GLOBOCAN estimates of incidence and mortality worldwide for 36 cancers in 185 countries. CA Cancer J Clin 2018 Nov;68(6):394-424. [doi: 10.3322/caac. 21492] [Medline: 30207593 ]

2. Althubiti MA, Nour Eldein MM. Trends in the incidence and mortality of cancer in Saudi Arabia. Saudi Med J 2018 Dec;39(12):1259-1262. [doi: 10.15537/smj.2018.12.23348] [Medline: 30520511]

3. Alharbi SH, Alreshidi FS, Ahmed IAB, Alrashidi AG, Alrashedi SA, Alshammeri KJK, et al. Assessment of knowledge and perception towards breast cancer prevention and early detection. Int J Med Res Health Sci 2018;7(1):65-76 [FREE Full text]

4. Al-Suroj HR, Al Ali FB, Al-Saleh KH. Awareness and attitude among Saudi females toward breast cancer screening in Al-Ahsa, KSA. Egypt J Hosp Med 2018 Apr;71(2):2516-2522. [doi: 10.12816/0045650]

5. Ibrahim EM, Zeeneldin AA, Sadiq BB, Ezzat AA. The present and the future of breast cancer burden in the Kingdom of Saudi Arabia. Med Oncol 2008;25(4):387-393. [doi: 10.1007/s12032-008-9051-5] [Medline: 18317955]

6. Jazieh AR, Da'ar OB, Alkaiyat M, Zaatreh YA, Saad AA, Bustami R, et al. Cancer incidence trends from 1999 to 2015 and contributions of various cancer types to the overall burden: Projections to 2030 and extrapolation of economic burden in Saudi Arabia. Cancer Manag Res 2019;11:9665-9674. [doi: 10.2147/CMAR.S222667] [Medline: 32009819]

7. Austoker J, Bankhead C, Forbes LJL, Atkins L, Martin F, Robb K, et al. Interventions to promote cancer awareness and early presentation: systematic review. Br J Cancer 2009 Dec 03;101(Suppl 2):S31-S39 [FREE Full text] [doi: 10.1038/sj.bjc.6605388] [Medline: 19956160 ]

8. Roth MY, Elmore JG, Yi-Frazier JP, Reisch LM, Oster NV, Miglioretti DL. Self-detection remains a key method of breast cancer detection for U.S. women. J Womens Health (Larchmt) 2011 Aug;20(8):1135-1139 [FREE Full text] [doi: 10.1089/jwh.2010.2493] [Medline: 21675875]

9. Linsell L, Forbes LJL, Kapari M, Burgess C, Omar L, Tucker L, et al. A randomised controlled trial of an intervention to promote early presentation of breast cancer in older women: effect on breast cancer awareness. Br J Cancer 2009 Dec 03;101(Suppl 2):S40-S48 [FREE Full text] [doi: 10.1038/sj.bjc.6605389] [Medline: 19956161]

10. Allen TL, Van Groningen BJ, Barksdale DJ, McCarthy R. The breast self-examination controversy: what providers and patients should know. J Nurse Practit 2010 Jun;6(6):444-451. [doi: 10.1016/j.nurpra.2009.11.005]

11. Oeffinger KC, Fontham ETH, Etzioni R, Herzig A, Michaelson JS, Shih YT, American Cancer Society. Breast cancer screening for women at average risk: 2015 guideline update from the American Cancer Society. JAMA 2015 Oct 20;314(15):1599-1614 [FREE Full text] [doi: 10.1001/jama.2015.12783] [Medline: 26501536]

12. Sait WA, Al-Amoudi SM, Tawatai DA, Abduljabbar HS. The knowledge of breast cancer among young Saudi females. Saudi Med J 2010;31(11):179-181.

13. Abdel-Aziz SB, Amin TT, Al-Gadeeb MB, Alhassar AI, Al-Ramadan A, Al-Helal M, et al. Perceived barriers to breast cancer screening among Saudi women at primary care setting. Asian Pac J Cancer Prev 2017 Sep 27;18(9):2409-2417 [FREE Full text] [doi: 10.22034/APJCP.2017.18.9.2409] [Medline: 28950697]

14. Alshahrani SM, Fayi KA, Alshahrani SH, Alahmari DS, Al Bejadi KM, Alahmari DM, et al. Assessment awareness of public about breast cancer and its screening measurements in Asir Region, KSA. Indian J Surg Oncol 2019 Jun;10(2):357-363 [FREE Full text] [doi: 10.1007/s13193-019-00899-5] [Medline: 31168262]

15. Gosadi IM. National screening programs in Saudi Arabia: Overview, outcomes, and effectiveness. J Infect Public Health 2019;12(5):608-614 [FREE Full text] [doi: 10.1016/j.jiph.2019.06.001] [Medline: 31248815]

16. El Bcheraoui C, Basulaiman M, Wilson S, Daoud F, Tuffaha M, AlMazroa MA, et al. Breast cancer screening in Saudi Arabia: free but almost no takers. PLoS One 2015;10(3):e0119051 [FREE Full text] [doi: 10.1371/journal.pone.0119051] [Medline: 25774520] 
17. Al-Hanawi MK, Hashmi R, Almubark S, Qattan AMN, Pulok MH. Socioeconomic inequalities in uptake of breast cancer screening among Saudi women: a cross-sectional analysis of a national survey. Int J Environ Res Public Health 2020 Mar 20;17(6):2056 [FREE Full text] [doi: 10.3390/ijerph17062056] [Medline: 32244881]

18. Al Dasoqi K, Zeilani R, Bawadi H, Al Dasoqi A. Perspectives and attitudes of Jordanian male college students on breast cancer screening. J Cancer Educ 2017 Mar;32(1):24-30. [doi: 10.1007/s13187-015-0909-x] [Medline: 26386596]

19. Al-Musa HM, Awadalla NJ, Mahfouz AA. Male partners' knowledge, attitudes, and perception of women's breast cancer in Abha, Southwestern Saudi Arabia. Int J Environ Res Public Health 2019 Aug 25;16(17):3089 [FREE Full text] [doi: 10.3390/ijerph16173089] [Medline: 31450695]

20. Al-Amoudi SM, Abduljabbar HS. Men's knowledge and attitude towards breast cancer in Saudi Arabia. A cross-sectional study. Saudi Med J 2012 May;33(5):547-550. [Medline: 22588817]

21. Al-Amoudi S, Eldeek B, Ayuob N, Alzhrani W, Alahwal M. Knowledge about breast cancer among male medical students, Jeddah, 2011. Life Sci J 2012;9(3):166-170.

22. Al-Amoudi S, AlHomied MTA, AlSayegh NYN, Radi ONI, Zagzoog MMS, Aloufi OFM, et al. Breast cancer knowledge among male high school students in Saudi Arabia. J Cancer Educ 2016 Dec;31(4):784-788. [doi: 10.1007/s13187-015-0951-8] [Medline: 26611278]

23. Statistical Yearbook of 2018. General Authority for Statistics, Kingdom of Saudi Arabia. 2018. URL: https://www.stats.gov.sa/ $\underline{\text { en/258 }}$ [accessed 2020-09-02]

24. Niksic M, Rachet B, Duffy SW, Quaresma M, Møller H, Forbes LJ. Is cancer survival associated with cancer symptom awareness and barriers to seeking medical help in England? An ecological study. Br J Cancer 2016 Sep 27;115(7):876-886 [FREE Full text] [doi: 10.1038/bjc.2016.246] [Medline: 27537388]

25. Mahfouz AA, Hassanein MHA, Nahar S, Farheen A, Gaballah II, Mohamed A, et al. Breast cancer knowledge and related behaviors among women in Abha City, southwestern Saudi Arabia. J Cancer Educ 2013 Sep;28(3):516-520. [doi: 10.1007/s13187-013-0495-8] [Medline: 23797712]

26. Lu H, Xie J, Gerido LH, Cheng Y, Chen Y, Sun L. Information needs of breast cancer patients: theory-generating meta-synthesis. J Med Internet Res 2020 Jul 28;22(7):e17907 [FREE Full text] [doi: 10.2196/17907] [Medline: 32720899]

27. Kukafka R, Yi H, Xiao T, Thomas P, Aguirre A, Smalletz C, et al. Why breast cancer risk by the numbers is not enough: evaluation of a decision aid in multi-ethnic, low-numerate women. J Med Internet Res 2015 Jul 14;17(7):e165 [FREE Full text] [doi: 10.2196/jmir.4028] [Medline: 26175193]

28. Palència L, Espelt A, Rodríguez-Sanz M, Puigpinós R, Pons-Vigués M, Pasarín MI, et al. Socio-economic inequalities in breast and cervical cancer screening practices in Europe: influence of the type of screening program. Int J Epidemiol 2010 Jun;39(3):757-765. [doi: 10.1093/ije/dyq003] [Medline: 20176587]

29. Kelly DM, Estaquio C, Léon C, Arwidson P, Nabi H. Temporal trend in socioeconomic inequalities in the uptake of cancer screening programmes in France between 2005 and 2010: results from the Cancer Barometer surveys. BMJ Open 2017 Dec 14;7(12):e016941 [FREE Full text] [doi: 10.1136/bmjopen-2017-016941] [Medline: 29247085]

30. Ameade EPK, Amalba A, Kudjo T, Kumah MK, Mohammed BS. Reducing the breast cancer menace: the role of the male partner in Ghana. Asian Pac J Cancer Prev 2014;15(19):8115-8119 [FREE Full text] [doi: 10.7314/apjcp.2014.15.19.8115] [Medline: 25338993]

31. Alotaibi RM, Rezk HR, Juliana CI, Guure C. Breast cancer mortality in Saudi Arabia: Modelling observed and unobserved factors. PLoS One 2018;13(10):e0206148 [FREE Full text] [doi: 10.1371/journal.pone.0206148] [Medline: 30347002]

32. Anastasi N, Lusher J. The impact of breast cancer awareness interventions on breast screening uptake among women in the United Kingdom: A systematic review. J Health Psychol 2019 Jan;24(1):113-124. [doi: 10.1177/1359105317697812] [Medline: 28810435]
Abbreviations
BSE: breast self-examination
CBE: clinical breast examination
KSA: Kingdom of Saudi Arabia
SR: Saudi Riyal 
Edited by $R$ Kukafka; submitted 31.10.20; peer-reviewed by C Jacob, AJ Nagarajan; comments to author 24.12.20; revised version received 29.12.20; accepted 31.01.21; published 25.02.21

Please cite as:

Sabgul AA, Qattan AMN, Hashmi R, Al-Hanawi MK

Husbands' Knowledge of Breast Cancer and Their Wives'Attitudes and Practices Related to Breast Cancer Screening in Saudi Arabia: Cross-sectional Online Survey

J Med Internet Res 2021;23(2):e25404

URL: https://www.jmir.org/2021/2/e25404

doi: $\underline{10.2196 / 25404}$

PMID: 33629959

(C)Afnan Abdulnasir Sabgul, Ameerah M N Qattan, Rubayyat Hashmi, Mohammed Khaled Al-Hanawi. Originally published in the Journal of Medical Internet Research (http://www.jmir.org), 25.02.2021. This is an open-access article distributed under the terms of the Creative Commons Attribution License (https://creativecommons.org/licenses/by/4.0/), which permits unrestricted use, distribution, and reproduction in any medium, provided the original work, first published in the Journal of Medical Internet Research, is properly cited. The complete bibliographic information, a link to the original publication on http://www.jmir.org/, as well as this copyright and license information must be included. 